\title{
Comparison of Hypoglycaemic Responses to Human Growth Hormone and the Synthetic 4-15 Fragment Between 16-18 Day-Old and 45-50 Day-Old Rats
}

\author{
F. M. Ng and J. Bornstein \\ Department of Biochemistry, Monash University, Clayton, Victoria, Australia
}

\begin{abstract}
Summary. The hypoglycaemic response to human growth hormone and its synthetic 4-15 fragment were studied in 16-18 day-old and 45-50 day-old normal male rats using three different bioassay system: (1) intravenous insulin tolerance tests, (2) insulin binding to specific receptor of hepatic plasma membranes, and (3) activation of insulin-dependent glycogen synthase in muscle. The mean level of the endogenous growth hormone in the 16-18 day-old group was $11 \pm$ $4 \mathrm{ng} / \mathrm{ml}$ and that of the $45-50$ day-old group was $164 \pm 35 \mathrm{ng} /$ $\mathrm{ml}$. A hypoglycaemic action of human growth hormone was observed in the baby animals but not in the adults. The synthetic 4-15 fragment was found, at a similar dose to that of the intact molecule, to enhance hypoglycaemia in both groups of
\end{abstract}

rats. In exact parallel, growth hormone increased hepatic insulinbinding and activated muscle glycogen synthase only in baby rats but the synthetic $4-15$ fragment affected both baby and adult animals in the same way. The molecular mechanism for the diminution of the responses to the intact molecule of growth hormone in normal adult rats remains to be identified. However, the present studies provide the first evidence on the hypoglycaemic response to growth hormone in vivo in normal rats without any previous chemical or surgical treatment.

Key words: Rats, human growth hormone, hypoglycaemia, insulin receptors, glycogen metabolism.
Numerous studies have demonstrated that the levels of endogenous growth hormone $(\mathrm{GH})$ influence insulin action in vitro and in vivo [1-4]. Current evidence, however, suggests that the entire molecule of $\mathrm{GH}$ is not always required to elicit the biological activities of the hormone $[5,6]$. Studies with various synthetic fragments of human $\mathrm{GH}$ showed that amino-terminal fragments containing the sequence $\mathrm{H}_{2} \mathrm{~N}$-Arg-Leu-Phe-Asp-AsnAla-COOH (human GH 8-13) potentiate the action of insulin by increasing the binding of insulin to specific receptors at target tissues and modulating the activities of insulin-dependent enzymes such as glycogen synthase and phosphorylase [7-9]. In the present study we have compared two groups of normal rats with different levels of endogenous $\mathrm{GH}$ in response to the hypoglycaemic action of human $\mathrm{GH}$ and a synthetic fragment of the molecule, $\mathrm{H}_{2} \mathrm{~N}$-Ile-Pro-Leu-Ser-Arg-Leu-PheAsp-Asn-Ala-Met-Leu-COOH (human GH 4-15).

\section{Materials and Methods}

\section{Materials}

Human GH was a gift from Institut Choay, Paris, France. Human GH 4-15 was synthesized and purified as described previously [10]. Twice recrystallized beef insulin was generously supplied by the Commonwealth Serum Laboratories, Melbourne, Australia. Sodium $\left.{ }^{125} \mathrm{I}\right]-$ iodide was obtained from the Radiochemical Centre, Amersham, UK. Insulin was iodinated to a specific activity of $80-100 \mu \mathrm{Ci} / \mu \mathrm{g} \mathrm{ac}-$ cording to the method of Freychet et al. [11].

\section{Animals}

Male albino Wistar rats (aged $45-50$ days) with a body weight ranging from $100-120 \mathrm{~g}$ were used as the adult animals. They were housed under control conditions at a constant temperature $\left(25^{\circ} \mathrm{C}\right)$, a normal 12-h light cycle and fed according to a synchronized schedule as described previously [12]. The pre-weaning baby rats were housed with their mothers for 16-18 days after birth, and removed shortly before use. At this age they weighed $25-30 \mathrm{~g}$. The male baby rats in each litter were equally divided into control and test groups for experiments.

\section{Studies in Vivo}

The acute effects of human $\mathrm{GH}$ and synthetic peptide human GH 4-15 on basal blood glucose and plasma insulin levels were determined on 16-18 day-old baby rats and 45-50 day-old, fasted overnight, adult rats. The test substances $(0.10-0.15 \mu \mathrm{mol} / \mathrm{kg}$ body weight) were given intravenously, and blood samples (25-100 $\mu$ l) were collected from the tail vein of pentobarbital-anaesthetized animals $30 \mathrm{~min}$ after IV injection. Blood glucose was estimated immediately on collection by the glucose oxidase method using a Yellow Springs Model 23 AM glucose analyser. Plasma insulin was assayed by the doubleantibody radioimmunoassay [13]. Plasma GH was determined by ra- 
Table 1. Effect of human growth hormone and the 4-15 fragment on basal blood glucose levels and activities of muscle glycogen synthase in $45-50$ day-old (adult) and 16-18 day-old (baby) normal male rats

\begin{tabular}{|c|c|c|c|c|c|c|}
\hline \multirow[t]{2}{*}{ Rats } & \multicolumn{3}{|c|}{ Blood glucose $(\mathrm{mmol} / 1)-$} & \multicolumn{3}{|c|}{ Activity ratio $\left(\frac{I}{I+D}\right)$ of glycogen synthase } \\
\hline & Control & Human GH & Human GH 4-15 & Control & Human $\mathrm{GH}$ & $\begin{array}{l}\text { Human GH } \\
4-15\end{array}$ \\
\hline $45-50$ day-old & $\begin{array}{l}5.96 \pm 0.22 \\
(16)\end{array}$ & $\begin{array}{l}6.05 \pm 0.41 \\
(8) \\
\text { NS }\end{array}$ & $\begin{array}{l}5.30 \pm 0.20 \\
(8) \\
p<0.025\end{array}$ & $\begin{array}{l}0.308 \pm 0.018 \\
(6)\end{array}$ & $\begin{array}{l}0.313 \pm 0.015 \\
(6) \\
\mathrm{NS}\end{array}$ & $\begin{array}{l}0.401 \pm 0.022 \\
(6) \\
p<0.0025\end{array}$ \\
\hline
\end{tabular}

Saline or test substances at a dose as indicated in the text were given IV $30 \mathrm{~min}$ before taking blood samples for glucose estimation. The activities of glycogen synthase from control and treated rats are expressed as the fraction of enzyme present in the active form (I). Results expressed as mean \pm SEM; number of animals in each group is given in parentheses. Significance of comparison with control was determined by Student's t-test for unpaired values. NS $=$ not significant

dioimmunoassay, using materials supplied by the National Institute of Arthritis, Metabolism and Digestive Diseases, Bethesda, USA

Intravenous insulin tolerance tests were performed on control and treated rats of both age groups. As previously described [14], all IV insulin tolerance tests were carried out at $09.45 \mathrm{~h}, 45 \mathrm{~min}$ after induction of anaesthesia by the IP injection of pentobarbital at a dose of either $60 \mathrm{mg}$ (for adult rats) or $40 \mathrm{mg}$ (for baby rats) $/ \mathrm{kg}$ body weight. The basal blood glucose levels of all animals used for IV insulin tolerance tests were within the range $5.2-5.8 \mathrm{mmol} / 1$.

\section{Preparation of Hepatic Plasma Membrane}

Overnight fasted 16-18 day-old baby rats or 45-50 day-old adult rats were divided into three groups. One test group was injected IV with human $\mathrm{GH}(0.15 \mu \mathrm{mol} / \mathrm{kg})$; the other test group with synthetic human $\mathrm{GH}(0.10 \mu \mathrm{mol} / \mathrm{kg})$ and the control group with an equivalent volume of physiological saline $(0.9 \% \mathrm{NaCl})$. Thirty minutes after injection, blood samples were collected for glucose and insulin analyses and immediately after, the animals were killed by decapitation. Hepatic plasma membranes were prepared following the method of Ray [15] and stored at $-70^{\circ} \mathrm{C}$. Membrane protein was measured by the method of Lowry et al. [16].

\section{Insulin Binding Studies}

Studies of binding of insulin to hepatic plasma membranes of control and pretreated rats of both age groups were conducted at $25^{\circ} \mathrm{C}$ in $50 \mathrm{mmol} / 1$ Tris- $\mathrm{HCl}$ buffer ( $\mathrm{pH} 7.5$ ) containing $0.5 \%$ bovine serum albumin according to the technique of Freychet et al. [17]. Aliquots of plasma membrane $(200 \mu \mathrm{g} / \mathrm{ml}$ of membrane protein) were incubated with $\left[{ }^{125} \mathrm{I}\right]$-insulin $(1 \mathrm{ng} / \mathrm{ml})$ in the presence or absence of unlabelled hormone for $30 \mathrm{~min}$. Immediately after incubation, the membranebound hormone was recovered by centrifugation of triplicate samples for 2 min with a Beckman Microfuge $B$ and radioactivity estimated using a Philips automatic gamma analyser (model PW 4520).

\section{Assays of Muscle Glycogen Synthase}

Both control and test rats of the two different age groups were anaesthetized and pretreated as those for insulin binding studies. From the animals a portion of hind leg muscle was removed [18], tissue homogenates prepared according to the method of Danforth et al [19] and the enzyme activity assayed as described by Thomas et al [20].

\section{Statistical Analysis}

Results are presented as mean \pm SEM. Differences in means were analyzed by the Student's t-test. All $p$ values of $<0.05$ were accepted as statistically significant.

\section{Results}

\section{Basal Levels of Blood Glucose, Plasma Insulin and Growth Hormone}

The 40-50 day-old and the 16-18 day-old groups of normal rats had similar basal levels of blood glucose $(6.2 \pm 0.4$ versus $5.8 \pm 0.3 \mathrm{mmol} / 1)$ and plasma insulin $(40.1 \pm 9.4$ versus $36.8 \pm 6.0 \mathrm{mU} / 1)$, but the levels of plasma GH in the adult rats were markedly higher than those of the baby rats $(164 \pm 35$ versus $11 \pm 4 \mathrm{ng} / \mathrm{ml})$.

\section{Effects of Human GH and Human GH 4-15 on Blood Glucose and Muscle Glycogen Synthase Activity}

Single IV injection of rats with either intact human GH $(0.15 \mu \mathrm{mol} / \mathrm{kg})$ or synthetic human GH $4-15$ $(0.10 \mu \mathrm{mol} / \mathrm{kg})$ produced no significant change in the levels of plasma insulin in both groups of rats (results not shown). In baby rats similar acute treatment with the same dose of GH lowered the levels of blood glucose for $45 \mathrm{~min}$ reaching a minimum $30 \mathrm{~min}$ after injection, but in adult rats it had no observable effect in the same period of time. Synthetic human GH 4-15 induced a significant decrease of blood glucose from 6.18 \pm 0.18 to $5.45 \pm 0.26 \mathrm{mmol} / 1(p<0.0125)$ in baby rats and from $5.96 \pm 0.22$ to $5.30 \pm 0.20 \mathrm{mmol} / 1(p<$ 0.025 ) in adult rats (Table 1). The data also showed that synthetic human GH 4-15 increased the proportion of the active form of muscle glycogen synthase in both groups of normal rats. Acute treatment with intact human GH in baby rats similarly activated the glycogenmetabolizing enzyme, but in adult rats no alteration of the enzyme activity was observed (Table 1).

\section{Effects on Insulin Sensitivity}

The hypoglycaemic effect of human $\mathrm{GH}$ and human GH 4-15 was demonstrated with IV insulin tolerance tests on the two groups of rats (Fig.1). Both the intact hormone and the synthetic peptide significantly poten- 


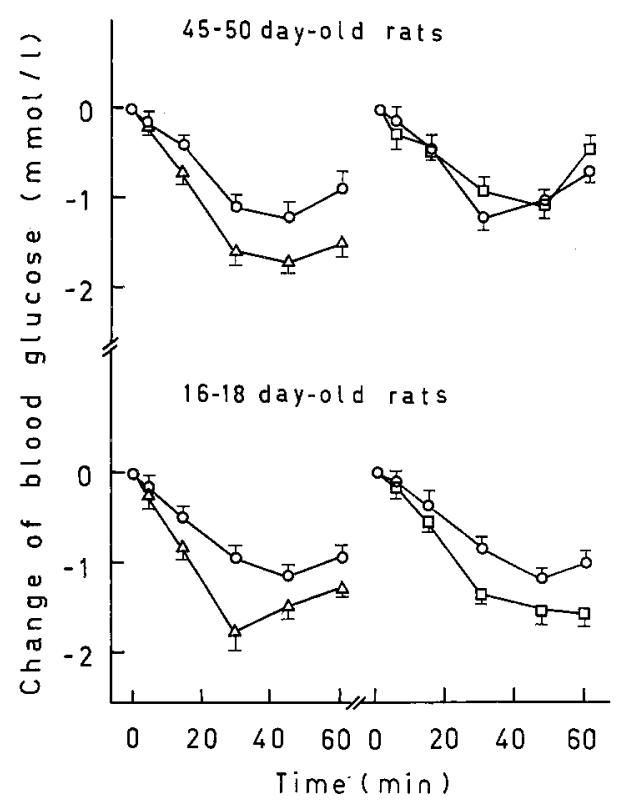

Fig. 1. Effect of human growth hormone and the synthetic 4-15 fragment in 45-50 day-old (adult) and 16-18 day-old (baby) rats during IV insulin tolerance tests. Data are expressed as mean \pm SEM of 12 animals from each group. Human growth hormone (right-hand panel, $\square)$ and the synthetic 4-15 fragment (left-hand panel, $\triangle$ ) were administered IV $5 \mathrm{~min}$ before the tests. From 15-60 min after the commencement of the IV insulin tolerance tests, the blood glucose in the baby rat pretreated with human growth hormone or the synthetic 4-15 fragment and the adult rats pre-treated with the synthetic 4-15 fragment were significantly lower $(p<0.05)$ than that of the respective control groups $(O)$. No significant change was detected at any time between the adult rats pre-treated with human growth hormone and the corresponding control rats $(\mathrm{O})$

tiated the action of exogenously administered insulin in 16-18 day-old baby rats. The synthetic human GH 4-15 showed similar activity but $\mathrm{GH}$ was devoid of such effect in $45-50$ day-old adult rats.

\section{Insulin Binding}

Figure 2 depicts the effect of human $\mathrm{GH}$ and human GH 4-15 in modulating the binding of $\left[{ }^{125} \mathrm{I}\right]$-insulin to hepatic plasma membrane receptors in vivo in the two different age groups of normal rats. In exact parallel with the results of IV insulin tolerance tests, marked increases were observed in the binding of insulin by hepatic plasma membranes prepared from all pretreated rats with the exception of GH-treated 45-50 day-old rats. The actual experimental data are presented as bound to free ratio $(\mathrm{B} / \mathrm{F})$ of $\left[{ }^{125} \mathrm{I}\right]$-insulin as a function of bound hormone (B) as described by Scatchard [21]. The plots suggested that the differences in binding were due to an increased number of active receptors.
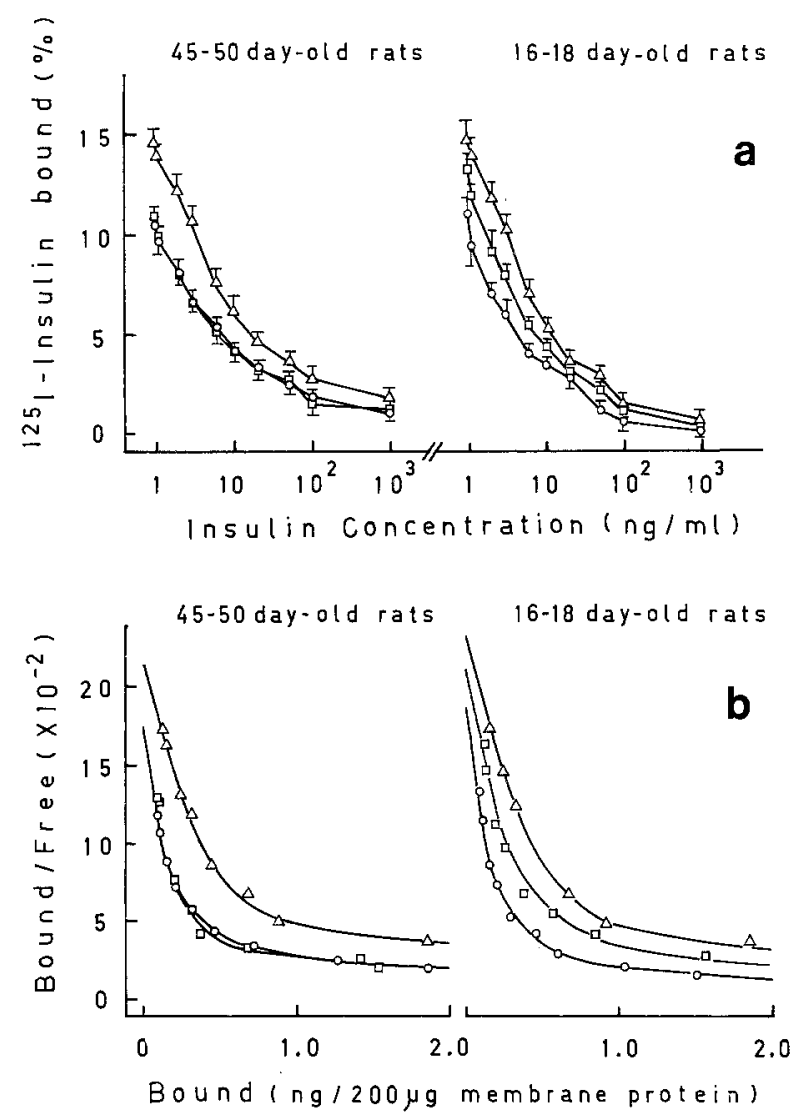

Fig. $2 a$ and $b$. Insulin binding to hepatic plasma membranes from control (O), human growth hormone-treated $(\square)$ and the synthetic 4-15 fragment-treated $(\triangle)$ rats of two different age groups.

a The percentages of ${ }^{125} \mathrm{I}$-insulin bound to various membrane preparations in the presence of increasing concentrations of unlabelled insulin. Data are corrected for non-specific binding and represent the mean \pm SEM of eight rats from each group.

b Scatchard analysis of data derived from the same series of experiments as in a

\section{Discussion}

A hypoglycaemic response to $\mathrm{GH}$ occurs consistently in hypophysectomized animals, and attempts to demonstrate this physiological response in normal animals have been proved disappointing. However, it is currently suggested that the response may be related to the elimination of endogenous GH [2, 22-25]. As hypophysectomy induces drastic alterations in the regulatory mechanism of the endocrine systems, it is difficult to ascertain that the induced hypoplycaemic response of the hypophysectomized animals is not due to physiological factors other than GH. Studies in animals without any prior chemical or surgical intervention would certainly provide a better understanding of the actions of GH under normal physiological conditions. Experiments in the present study were designed specifically to maintain these normal physiological conditions, thus utilizing only normal animals. For many years it has been recognized that the levels of endogenous GH in rats vary with 
age and are at the lowest from days 5-20 after birth [26, 27]. Normal baby rats of 16-18 days of age were, therefore, chosen for comparison with adult rats of 45-50 days of age in the present studies of the hypoglycaemic actions of human $\mathrm{GH}$ and its synthetic fragment human GH 4-15. The mean level of endogenous GH in the baby rats was significantly lower than that of the adult animals. The hypoglycaemic responses to exogenous intact $\mathrm{GH}$ are also quite different in the two different age groups of rats.

Acute $\mathrm{GH}$ administration had no significant effect on blood glucose levels in adult rats; this is consistent with previous evidence obtained from investigations in rats [28] and in man [4, 29]. The absence of a correlation between endogenous $\mathrm{GH}$ and blood glucose in normal animals also cast doubt on the role of the intact GH molecule in glucose homeostasis. In the studies of lipolytic activity of highly purified GH, Frigeri observed that the biological activity is not due to the intact peptide but rather a low molecular weight fragment or a cleaved form of $\mathrm{GH}$ [30]. This observation in vitro is supported by the present finding in vivo that the synthetic fragment of human $\mathrm{GH} 4-15$, but not intact $\mathrm{GH}$, induced hypoglycaemia in normal adult rats. The data reported here not only substantiate the concept that the amino-terminal region of the human $\mathrm{GH}$ molecule might be responsible for the hypoglycaemic action of the hormone [31], but also suggest the further possibility that the absence of hypoglycaemic response to human $\mathrm{GH}$ in adult rats is associated with the impairment of the cellular mechanism to initiate the proteolytic activation of GH and subsequently to release the active hypoglycaemic fragments from the molecule for the regulation of glucose metabolism. The only evidence in this regard to date is the isolation of a urinary peptide fraction which had the same biological actions as the synthetic fragment [14]. Unfortunately, it is still impossible to identify the urinary material definitively, and elucidation must wait for its purification and the sequencing of its structure.

The results with the 16-18 day-old rats show that the baby animals responded to the hypoglycaemic action of both human $\mathrm{GH}$ and the synthetic human $\mathrm{GH} 4-15$ fragment equally well. The exogenous $\mathrm{GH}$ at pharmacological doses clearly enhanced insulin-sensitivity in insulin tolerance tests, increased binding of insulin to the specific receptors, and activated the insulin-dependent intracellular glycogen synthase. At similar doses the synthetic human GH 4-15 appears to be equally, if not more, potent as intact human GH in all parameters tested. While our experiments unequivocally show the difference in the hypoglycaemic response to $\mathrm{GH}$ between baby and adult rats, the molecular mechanisms underlining this occurrence remain essentially unknown. Our observations are consistent with the idea of Goodman, that the insensitivity to the hypoglycaemic effect of growth hormone in normal animals is produced by growth hormone itself [22]. Our experiments cannot rule out the influence of other physiological factors such as changes in hormonal profiles other than $\mathrm{GH}$ and insulin in the two different age groups of animals. However, these studies provide the first evidence in vivo on the hypoglycaemic response to $\mathrm{GH}$ in normal rats without any prior chemical or surgical treatment. The present findings suggest that an impaired mechanism(s) in the proteolytic release of the hypoglycaemic fragments from the intact $\mathrm{GH}$ or the proteolytic modification of the molecule may contribute to the absence of response in adult animals.

Acknowledgements. The authors wish to acknowledge the contributions of S. Bechervaise, J. Bromley and P.Larsen-Disney during the course of this research. This project was supported by a project grant of National Health and Medical Research Council of Australia and a Special Research Fund grant of Monash University, Victoria, Australia.

\section{References}

1. Maloff BL, Levine JH, Lockwood DH (1980) Direct effects of growth hormone on insulin action in rat adipose tissue maintained in vitro. Endocrinology 107:538-544

2. Schwarz J (1980) Enhanced sensitivity to insulin in rat treated with antibodies to rat growth hormone. Endocrinology 107: 877-883

3. Luft R (1969) The effects of moderate and high doses of human growth hormone on the insulin response to glucose infusion in prediabetic subjects. Horm Metab Res 1: 111-118

4. Metcalfe P, Johnston DG, Nosadini R, Ørksov H, Alberti KGMM (1981) Metabolic effects of acute and prolonged growth hormone excess in normal and insulin deficient man. Diabetologia 20: $123-128$

5. Kostyo JL, Wilhelmi AE (1976) Conference on the structure-function relationship of pituitary growth hormone: a report. Metabolism 25: 105-124

6. Paladini AC, Pena C, Retegui LA (1979) The intriguing nature of the multiple action of growth hormone. Trends Biochem Sci 4: 256-260

7. Ng FM, Bornstein J (1979) Insulin-potentiating action of a synthetic amino-terminal fragment of human growth hormone $(\mathrm{hGH}$ 1-15) in streptozotocin-diabetic rats. Diabetes 28: 1126-1130

8. Sims P, Ng FM, Bornstein J (1980) Modulation of adipocytes insulin receptors by a human growth hormone fragment. Biochem Int 1: $120-125$

9. Ng FM, Bornstein J, Pullin CO, Bromley JO, Macaulay SL (1980) The minimal amino acid sequence of the insulin-potentiating fragments of human growth hormone. Diabetes 29: 782-787

10. Pullin CO, Harcourt JA, Ng FM, Bornstein J (1981) The insulin potentiating action of human growth hormone - synthesis and activity of $\mathrm{N}$-terminal fragments. Int $\mathfrak{J}$ Peptide Protein Res 18: 318-323

11. Freychet P, Roth J, Neville DM (1971) Monoiodoinsulin: demonstration of its biological activity and binding to fat cell and liver membranes. Biochem Biophys Res Commun 43: 400-408

12. Ng FM, Larner J (1976) Actions of insulin-potentiating peptides on glycogen synthesis. Diabetes 25: 413-419

13. Desbuquois B, Aurbach GH (1971) Use of polyethylene glycol to separate free and antibody-bound peptide hormones in radioimmunoassays. J Clin Endocrinol Metab 33: 732-738

14. Ng FM, Zimmet PZ, Seiler G, Taft P, Bornstein J (1974) Insulinpotentiating action of a peptide fraction from human urine. Diabetes 23: $950-956$

15. Ray TK (1970) A modified method for the isolation of the plasma membrane from rat liver. Biochem Biophys Acta 196: 1-9

16. Lowry DH, Rosebrough WJ, Farr AL, Randall RJ (1951) Protein 
measurement with the folin phenol reagent. J Biol Chem 193: 265-275

17. Freychet P, Roth J, Neville DM (1971) Insulin receptors in the liver: specific binding of ${ }^{125} \mathrm{I}$-insulin to the plasma membrane and its relation to insulin bioactivity. Proc Natl Acad Sci USA 168: 1833-1837

18. Newman JD, Armstrong J McD, Bornstein J (1978) Effects of part sequences of human growth hormone on in vivo hepatic glycogen metabolism in the rat. Biochem Biophys Acta 544: 234-244

19. Danforth WH, Helmreich E, Core CE (1971) The effect of contraction and of epinephrine on the phosphorylase activity of frog sartorius muscle. Proc Natl Acad Sci USA 168: 1833-1837

20. Thomas JA, Schlender KK, Larner J (1968) A rapid filter paper assay for UDP glucose-glycogen glucosyltransferase including an improved biosynthesis of UDP- ${ }^{14} \mathrm{C}$-glucose. Anal Biochem: 25: 486-499

21. Scatchard G (1949) The attractions of proteins for small molecules and ions. Ann NY Acad Sci 51: 660-672

22. Goodman HM (1968) Growth hormone and the metabolism of carbohydrate and lipid in adipose tissue. Ann NY Acad Sci 148: 419-440

23. Kahn CR, Goldfine ID, Neville DM, De Meyts P (1978) Alterations in insulin binding induced by changes in vivo in the levels of glucocorticoids and growth hormone. Endocrinology 103: 1054-1066

24. Binbaum RS, Goodman HM (1979) Comparison of several insulin-like effects of growth hormone. Horm Metab Res 11: 136-141

25. Goodman HM, Coiro V (1981) Induction of sensitivity to the insulin-like action of growth hormone in normal rat adipose tissue. Endocrinology 108: 113-119
26. Strosser M Th, Mialhe $P$ (1975) Growth hormone secretion in the rat as a function of age. Horm Metab Res 7: 275-278

27. Edén S (1979) Age- and sex-related differences in episodic growth hormone secretion in rat. Endocrinology 105: 555-560

28. Tannenbaum GS, Martin JB, Colle E (1976) Ultradian growth hormone rhythm in the rat: effects of feeding, hyperglycemia, and insulin-induced hypoglycemia. Endocrinology 99: 720-727

29. Quabbe HJ, Schilling E, Helge H (1966) Pattern of growth hormone secretion during a 24-hours fast in normal adults. J Clin Endocrin Metab 26: 1173-1177.

30. Frigeri LG (1980) Absence of in vitro dexamethasone-dependent lipolytic activity from highly purified growth hormone. Endocrinology 107: 738-743

31. Bornstein J, Armstrong J McD, Taft HP, Ng FM, Gould MK (1973) The mechanism of the diabetogenic effects of pituitary growth hormone. Postgrad Med J 49: 219-242

Received: 1 February 1982

and in revised form: 5 August 1982

Dr. Frank M. $\mathrm{Ng}$

Department of Biochemistry

Monash University

Clayton, 3168

Victoria, Australia 